
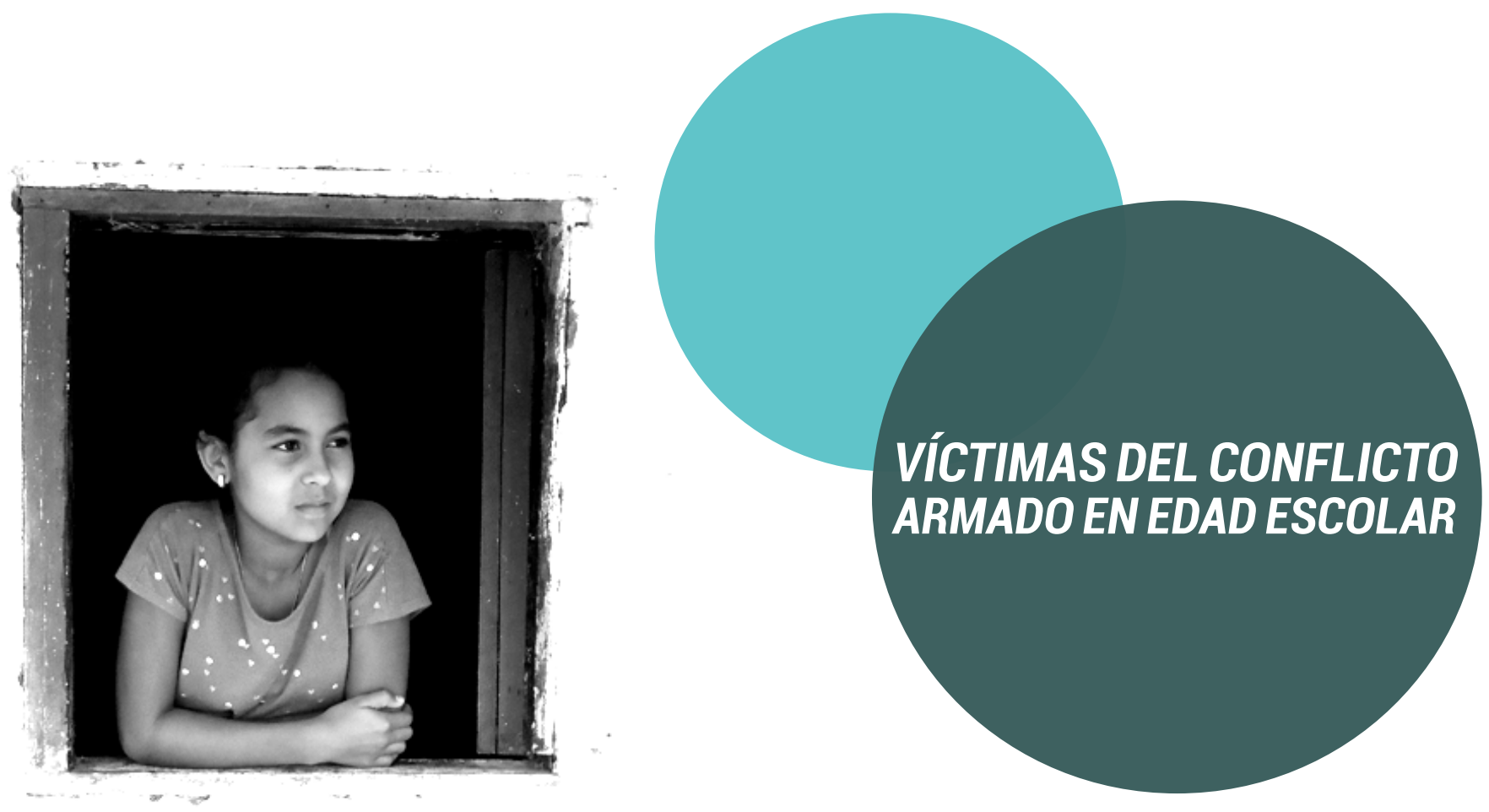

Al cierre de esta investigación se encontraban registradas en Colombia 7.821.641 víctimas del conflicto armado. El $24 \%$ de ellas vivió un hecho victimizante cuando se encontraba en edad escolar, es decir, entre los 6 y los 17 años. Para los expertos en educación consultados, cualquier hecho de violencia que repercuta sobre un menor tiene entre sus consecuencias la alteración de la vida académica.

\title{
Total víctimas del conflicto armado en edad escolar 1984-2015
}

6-12 años

1.178 .941

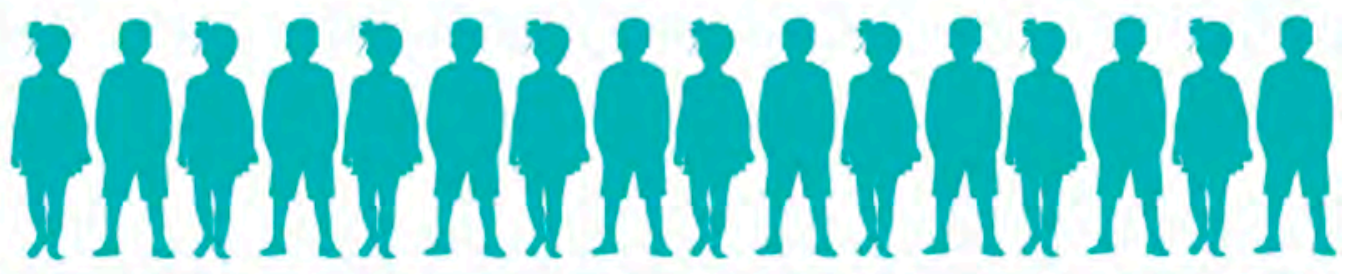

13-17 años

722.070

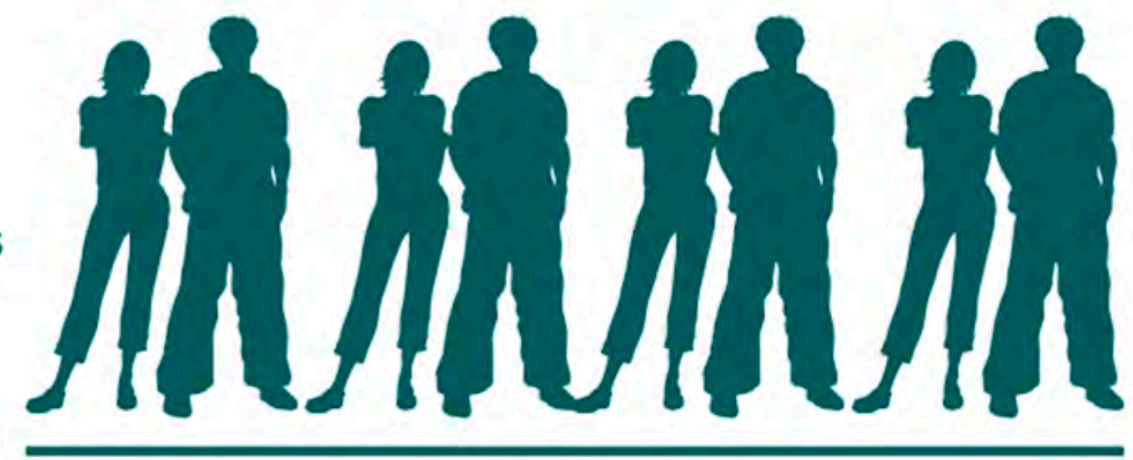

Datos a 1 de diciembre de 2015 


\section{HISTÓRICO VÍCTIMAS DEL CONFLICTO ARMADO EN EDAD ESCOLAR}

\section{6 a 12 Años}

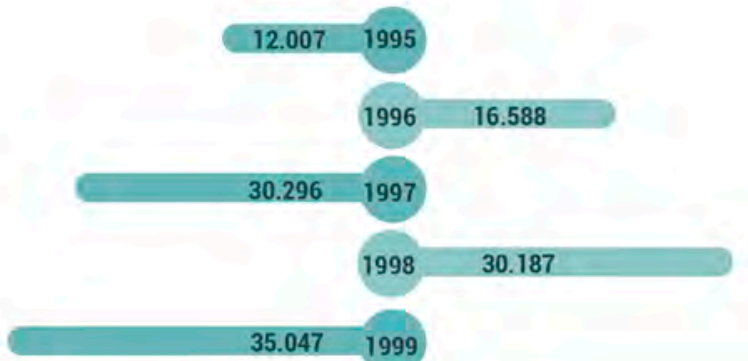

$2000 \quad 74.517$

$99.616 \quad 2001$

$2002 \quad 117.955$

$74.039 \quad 2003$

$2004 \quad 67.601$

$78.516 \quad 2005$

$2006 \quad 78.210$

$83.497 \quad 2007$

$2008 \quad 72.501$

$44.306 \quad 2009$

$2010 \quad 34.399$

$43.541 \quad 2011$

$2012 \quad 42.056$

$42.902 \quad 2013$

$2014 \quad 37.099$

$11.246 \quad 2015$ 


\section{HISTÓRICO VÍCTIMAS DEL CONFLICTO ARMADO EN EDAD ESCOLAR}

\section{3 a 17 Años}

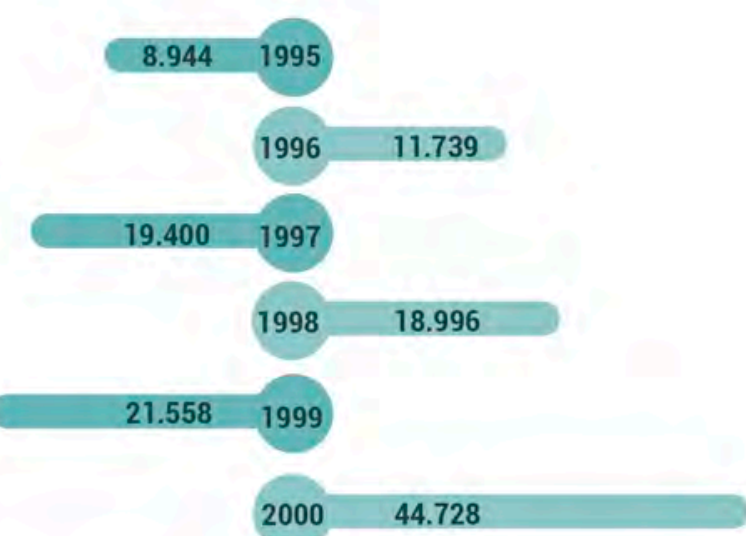

58.363

2001

$2002 \quad 69.488$

$43.978 \quad 2003$

$2004 \quad 40.331$

$45.881 \quad 2005$

$2006 \quad 45.639$

$49.351 \quad 2007$

$2008 \quad 43.726$

$27.527 \quad 2009$

$2010 \quad 21.194$

$26.487 \quad 2011$

$2012 \quad 26.278$

27.876

2013

$2014 \quad 23.834$

$6.950 \quad 2015$ 


\section{"La ley de víctimas solo está en el papel, y no hay}

alternativas de educación":

\section{LINA ORTIZ}

Lina Ortiz, víctima del conflicto armado, relata en esta entrevista cómo se cruza por el sistema escolar con una prótesis, que le recuerda en cada paso las zancadillas que coloca la guerra.

\section{¿En qué momento su nombre empieza a aparecer en las listas de víctimas del conflicto armado colombiano?}

A los trece años fui a visitar a mi papá, quien era miembro de la policía, a un municipio que se llama Saladoblanco, al sur del Huila. Nos encontrábamos mis dos hermanas, mi mamá y yo, aproximadamente a las 9:30 pm, en la estación de la policía, cuando unos subversivos de las Farc entraron en dicho puesto. Dentro del enfrentamiento, uno de los artefactos explosivos incursionó en mi pierna derecha destrozándola en su totalidad. Dos horas después intentamos salir de la estación pero los guerrilleros ya tenían el control de todo el lugar. Finalmente encontramos la forma de salir, y llegamos a un centro de salud muy pequeño para que me atendieran. Lastimosamente el médico del pueblo no estaba, y tampoco había medicamentos. Entonces, llegó un señor que estaba de visita y dijo que era médico. Él me prestó los primeros auxilios, pero ya no había nada que hacer con mi pierna.

\section{¿Qué tan fácil fue el reintegro al sistema educativo, luego del episodio narrado?}

La vida me cambió bastante. Tuve problemas para ingresar a un colegio público porque no cumplía con las mismas actividades que hacía cualquier otra persona de mi edad. Luego tuve la oportunidad de estudiar en un colegio privado donde sí entendieron mi situación. Fui seis meses en muletas porque en ese entonces la policía no me suministró la prótesis que requería, por lo que tuve que hacer muchos trámites para que me dieran mi primera prótesis.

\section{¿Ha recibido algún tipo de ayuda por parte del Estado para acceder a la educación?}

La Ley de Víctimas solo está en el papel y no hay alternativas de educación. Si hoy yo quiero seguir estudiando no voy a poder hacerlo si no es a través de la educación privada. Además, tengo que asumir los costos. Yo lo he intentado a través de créditos educativos del lcetex, donde hay condonaciones de intereses, pero es muy difícil. Se tiene que cumplir un sinnúmero de requisitos y con uno que no cumplas pierdes la oportunidad automáticamente.

Por lo que manifiesta es evidente que siente inconformidad frente a la Ley de Víctimas, ¿qué considera usted que le hace falta a la citada ley?

Para mí es muy importante la rehabilitación integral de una víctima. No solamente es darle una prótesis y presentarlas a la sociedad. Debe haber un acompañamiento psicológico, y en el plano educativo, en salud y en lo laboral. Uno quiere tener los medios para poder salir adelante y no que la misma sociedad y el mismo Estado lo limite a uno por el hecho de ser una víctima o tener una discapacidad. 


\section{"Cuando la fuerza pública también ocupa la escuela, el lugar se convierte en objetivo militar para la guerrilla": JORGE CALERO}

En Colombia la guerra se pasea descaradamente por los pasillos de las escuelas rurales. Los niños de Putumayo, Cauca, Antioquia, Nariño, entre otros departamentos, conocen la fuerza de sus pasos. Jorge Calero, Defensor delegado para la prevención de riesgos de violaciones de Derechos Humanos y Derecho Internacional Humanitario de la Defensoría del Pueblo, explica por qué ocurre esto y, además, cómo los estudiantes terminan siendo instrumento del conflicto.

¿Desde el sistema de alertas de la Defensoría del Pueblo, cuáles son las formas de violencia contra la escuela que más evidencian en el marco del conflicto armado?

Frente a la educación como derecho observamos que el impacto es grande viéndolo desde la perspectiva de cómo los actores armados ilegales tratan de realizar acciones violentas que vulneran bienes civiles como las escuelas. Al atacar las escuelas, que son bienes civiles protegidos por el Derecho Internacional Humanitario, docentes y niños terminan siendo víctimas. Como derecho fundamental, entonces, se ve un impacto en el acceso, la calidad y la permanencia de los niños en el sistema educativo, por el riesgo permanente de sufrir ataques, atentados, presiones e intimidaciones por parte de grupos ilegales que son la fuente generadora de riesgo.

\section{¿De qué manera los grupos armados ilegales intimidan a los menores de edad y con qué fin lo hacen?}

En zonas rurales, la mayor presencia de los grupos armados ilegales son las guerrillas, llámense Farc, ELN o la disidencia del EPL. Esas guerrillas encuentran en las escuelas el recurso humano que favorece sus fines, como el fortalecimiento de las filas. Para esto deben atraer a los niños, seducirlos para vincularlos como combatientes de estos grupos irregulares. Y la escuela, que es el entorno protector, también obviamente resulta siendo objeto del asedio de estos grupos, ya que ingresan a ella, porque buscan a los niños, porque violentan las escuelas. A veces, cuando la fuerza pública ocupa la escuela, el lugar se convierte en objetivo militar para la guerrilla, y los niños quedan en medio de ataques armados. O cuando alrededor de la escuela se siembran minas antipersonal, para evitar que la fuerza pública ocupe la escuela; $u$ ocupándola para que las unidades militares puedan caer en esos campos minados.

¿Además de las guerrillas, tienen ustedes información de cómo otros grupos ilegales llegan hasta las escuelas para vincular a menores de edad a sus organizaciones?

Si bien las Autodefensas Unidas de Colombia o los grupos que el Gobierno denomina Bacrim no realizan ataques armados o minan las escuelas (como sí lo hacen en Colombia los grupos guerrilleros), estas siguen siendo el establecimiento propicio para que ellos puedan contactar a los niños y jóvenes que están allí, para utilizarlos de forma ilícita. Son utilizados para fines como el sicariato, el micro tráfico y labores de vigilancia o inteligencia. Además, les ofrecen armas, motocicletas y medios de comunicación -celulares- para que sirvan de mensajeros. Es otro tipo de violencia contra las escuelas. 
Cauca: en Toribío - y en el norte del Cauca- hablemos de Caloto, Caldono, Jambaló, Buenos Aires, Silvia. En esos municipios se ha dado, de tiempo atrás, fuertes acciones de reclutamiento. Igual en Caquetá, estamos hablando de municipios como San Vicente del Caguán, Cartagena del Chairá, San José de Fragua. En Putumayo: Puerto Asís, San Miguel, Puerto Guzmán, Orito. En el Meta en municipios como Mesetas, Uribe, Vista Hermosa y Mapiripán. En Zonas del Guaviare como San José del Guaviare, en Calamar, El Retorno. En la provincia de Ocaña digamos Convención, Teorama, El Tarra, en Norte de Santander. En el Huila, en el Valle del Cauca, en Buenaventura. En Arauca en Tame, Fortul, Saravena. Es muy grande - de verdad- el número de municipios donde se presenta esto.

\section{¿La fragilidad del Estado en las zonas que nombra es la causa de la vulnerabilidad de los escolares?}

El elemento de la debilidad del Estado en las zonas rurales es una condición de vulnerabilidad. En muchas veredas y corregimientos- hay que decirlo con mucha tristeza- la única presencia de un uniforme es del actor armado ilegal. Y esa presencia implica control territorial, control social, imposición de normas y conductas. Hay zonas donde a la familia le imponen como cuota entregar un niño a la guerrilla, y si no lo entregan vienen retaliaciones contra la familia.

Acá hubo muchos casos de asedio a los albergues, aunque sé que eso ha disminuido. Los albergues son como los sitios donde los niños que viven lejos, en zona rural, duermen durante el fin de semana o entre semana porque no tienen acceso al transporte público para llegar a sus fincas o a sus veredas. Esos albergues fueron durante mucho tiempo asediados por los grupos de guerrilla y otros grupos ilegales para poder adoctrinar a los niños, para invitarlos a la guerra.

\section{¿De qué manera el Ejército también interviene- de forma ilegal- en las escuelas?}

La fuerza pública también ocupa las escuelas. Se han recibido muchas quejas de comunidades de diferentes departamentos del país donde se presentan estos hechos. ¿Qué departamentos?: el suroccidente del país hablando de Caquetá, Putumayo, Cauca, Valle del Cauca y Nariño. Igual Chocó, la zona de Catatumbo en Norte de Santander, el departamento de Arauca. La zona de los Llanos Orientales: Meta y Guaviare. Y la zona de Tierralta en Córdoba.

\section{¿Otro de los problemas es la cercanía de las bases militares y las estaciones de policía con las escuelas, qué información tienen sobre esto?}

El norte del Cauca ha sido una zona donde los niños y niñas han resultado muy afectados, al igual que en Putumayo y Caquetá. Estuvimos en Inzá- Cauca-, y el puesto de policía está ubicado cerca de dos escuelas. Entonces, cada vez que la guerrilla ataca el puesto de policía afecta el establecimiento educativo. Por eso, los niños deben salir despavoridos de la escuela en un plan de emergencia, y cuando no pueden salir deben esconderse debajo de los escritorios mientras pasa el ametrallamiento o pasa el lanzamiento de los morteros, de las granadas o de los proyectiles de armas de fuego. 


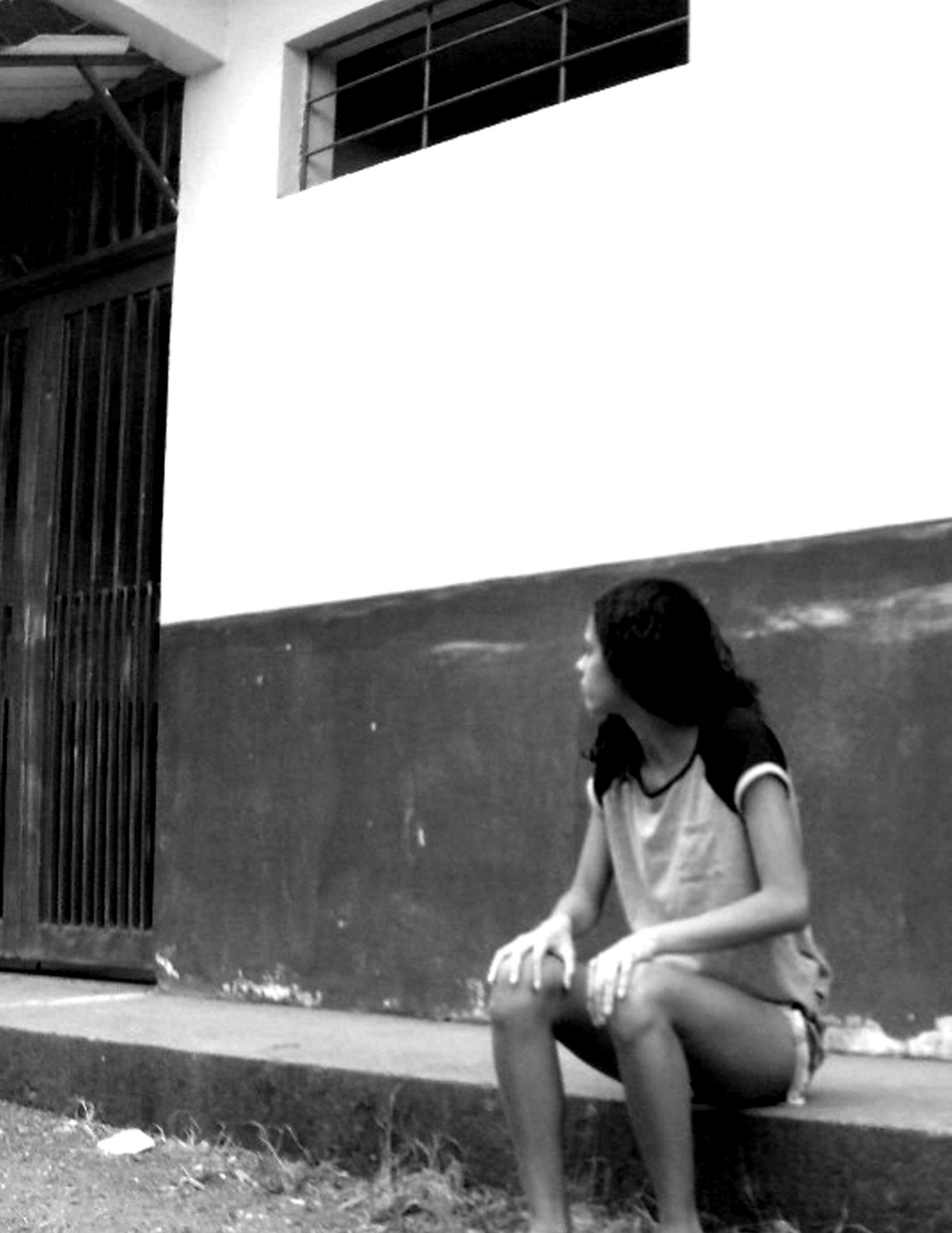

